\title{
Coin Insert Mobile Charger
}

\author{
Aditya Kamat \\ Student, Rajiv Gandhi Institute \\ of Technology, Mumbai, India
}

\author{
Aniket Kulkarni \\ Student, Rajiv Gandhi Institute \\ of Technology, Mumbai, India
}

\author{
Kumar Akshay \\ Student, Rajiv Gandhi Institute \\ of Technology, Mumbai, India
}

\author{
Raju Kasturi \\ Student, Rajiv Gandhi Institute of \\ Technology, Mumbai, India
}

\author{
Nazahat Balur \\ Electronics \& Telecommunications \\ Department, Rajiv Gandhi Institute \\ Technology, Mumbai, India
}

\begin{abstract}
Coin based mobile charging system provides an alternate solution to all mobile users for charging their mobile phones during travelling or in an emergency situation where they may not have conventional power banks. This system can also be implemented in commercial complexes and colleges where mobiles are not allowed. This system is based on Arduino UNO microcontroller which controls the entire system including provision of password based security for the mobile phones, once inserted in the slots. The paper also focuses on various applications of this system and how this system can be integrated so as to add more features, sustainability and reliability in it and solve the major problems faced by people related to charging their phones. The future scope of the system also revolves around implementing this system in rural areas where there are constant power failures.
\end{abstract}

\section{General Terms}

Charging, Mobile charger, Coin insert, Coin insertion machine, Microcontroller, Arduino

\section{Keywords}

Mobile charger, Coin insert, Coin insertion machine, Arduino

\section{INTRODUCTION}

The project is based on developing a coin insertion based mobile charging system which provides an effective solution to the low battery issues faced by everyone while traveling or during day to day activities. Most of the people use a smartphone, which consumes tremendous battery power. Within few hours of usage the mobile battery gets drained and the users either have to switch off their net packs or they have to use their mobile in power saving modes. At this time, users make use of power banks, which are readily available, but the availability of power banks is not a surety in each case. What if during the case of an emergency the mobile is switched off and there is an extremely urgent need to call someone or to check any email or respond to someone during traveling. Many times battery becomes low at the middle of a conversation particularly at inconvenient times when access to a standard charger isn't possible. Also at certain places such as colleges during exam time, as well as in many commercial complexes, people are asked to keep their mobile phones outside before entering the premises. This time can be a great utilization for charging their phones using the coin insert mobile charger, which would provide security as well as efficient charging at reasonable rates. This system is extremely user friendly and can charge the mobile along with providing security so that one can safely keep the mobile to charge for a particular period of time and come back to collect the recharged mobile. As shown in fig 1 below, the system involves a digital locker based system consisting of charging slots [1]. The users have to select the time for which they want to charge the phone and pay the charges using coin insertion system accordingly. Then the user needs to create a password for the locker which will provide security to the slot.

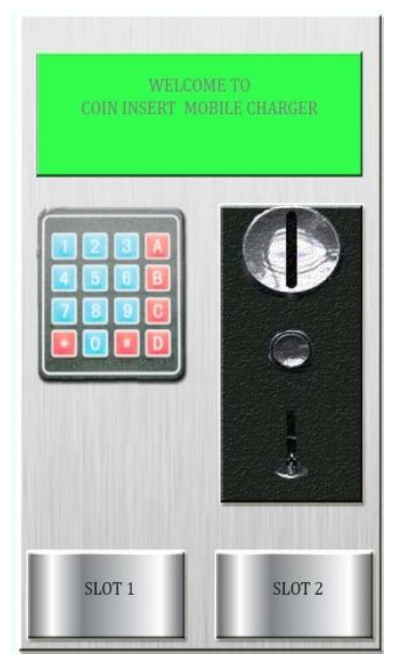

Fig 1: System Model

The user can keep his mobile in charging slot to charge and the slot will get locked so that no one other than the user can open it. An Arduino UNO is programmed for all the controlling applications including the password protection and locking system. This gives a clear idea about the charging system. The system can be installed in the places like malls, cafeterias, hospitals, railway stations, restaurants, colleges, airports and many more. The project was ideated considering the various issues particularly college students faced throughout their day. Based on a survey done, many of the students didn't have any safe source for charging their phones in case of an emergency. Hence the idea of implementing this system was formed. This project is implemented in the USA by a company called "Chargetech"[2], wherein it is used at public spots like malls and restaurants. The system can also be used to generate revenue by displaying advertisements on the cabinet. 


\section{SPECIFICATIONS AND INFORMATION ABOUT COMPONENTS USED:}

\subsection{Arduino Board}

Arduino Uno is a microcontroller board based on the ATmega328P. It has 14 digital input/output pins (of which 6 can be used as PWM outputs), 6 analog inputs, a $16 \mathrm{MHz}$ quartz crystal, a USB connection, a power jack, an ICSP header and a reset button. As shown in Fig 3, it contains everything needed to support the microcontroller [3]. In order to get it started, it is essential to simply connect it to a computer with a USB cable or power it with a AC-to-DC adapter or battery.

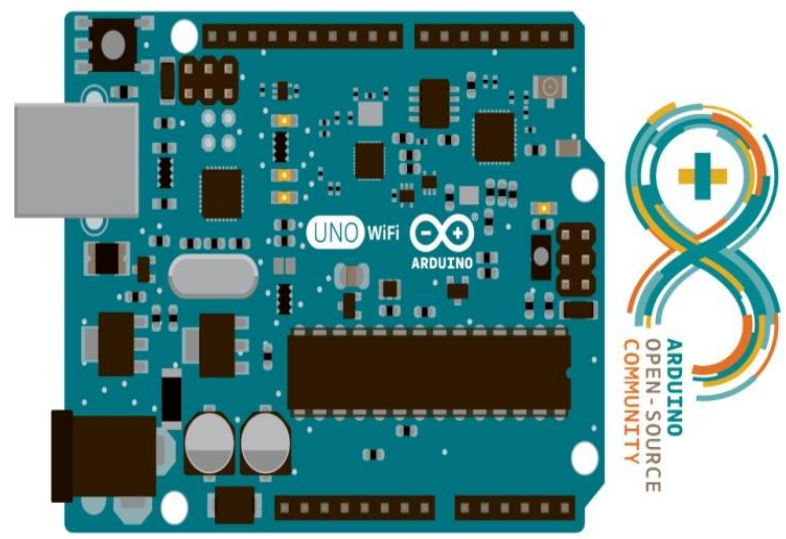

Fig 3: Arduino Board

\subsection{Coin insertion machine}

The coin insertion machine is a module which detects the coins and sends the value to the Arduino board or any other microcontroller. The working principle of the coin insertion machine is based on image processing techniques. Proper programming is essential for working of this project. Whenever using the machine for the first time, it needs to provide the values for the particular coin being inserted. Here a machine is proposed which can detect up to 4 coins i.e. 1 rs, $2 \mathrm{rs}, 5 \mathrm{rs}$ and $10 \mathrm{rs}$ coin. Initially it is an essential need to insert this coin inside the machine for a particular number of times and assign a value to that particular coin. Upon entering the coin, the sensor present inside the machine captures the image of the coin. After that, it is essential to insert the same coin in particular number of ways so that the machine sensor will capture all those images. Based on image processing techniques and after assigning a value to that coin, the machine detects properly all the coins. The coins which are fake or different will be rejected by the machine and the coins which are accepted will be stored in the coin-box which is present inside the system. Hence the coin insertion based module is very efficient to detect the coins and give output value accurately. The coin insertion machine [4] is shown in fig 4 .

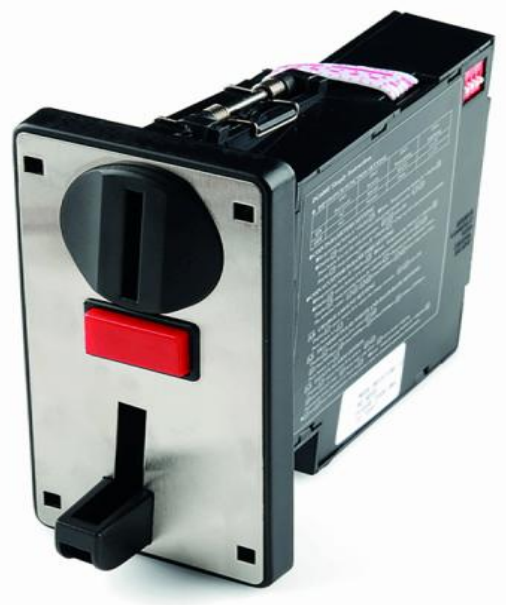

Fig 4: Coin Insertion Machine

\subsection{AC to DC Converter}

Electrical current enters the primary coil of the transformer and induces a current in the secondary coil, which has fewer coils, resulting in a lower voltage. This is a step down transformer. Little power is lost in this process because the amperage increases in relation to the decrease in voltage. A rectifier usually consists of 4 diodes arranged in a diamond shape a type called a bridge rectifier $\}$. A diode only allows current to pass in 1 direction; the diamond configuration allow 2 diodes to pass the positive half of the current and the other 2 diodes to pass the negative half. The output of both sets is a current that climbs from 0 volts to the maximum positive voltage. A capacitor stores an electrical charge for a short time and then releases it slowly. The input from the rectifier resembles a string of humps; the output of the "smoothing capacitor" is a somewhat steady voltage with ripples. The next stage is a regulator. This smoothens out the ripples and creates a very steady current that can operate electronic devices without damaging them. Regulators are integrated circuits and can either have fixed or variable output voltages. The AC to DC converter [5] is shown in fig 5.

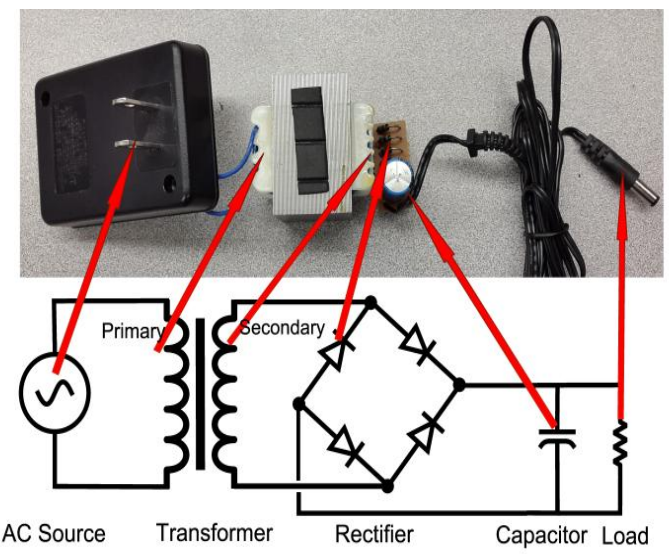

Figure 5: AC to DC Converter

\subsection{Matrix Array (4x4)}

The $4 * 4$ Matrix Array is basically used as a keypad in this system for the users to enter their choice of slots, charging times, rates, as well as passwords [6]. It consists of four rows and four columns of buttons which work as elements in a $4 * 4$ 
matrix, as shown in fig 6 below. The specifications of this component are given in the table 1, 2 and 3 .

Table 1: Specifications for electrical properties

\begin{tabular}{|c|c|}
\hline Specification & Value \\
\hline Contact resistance & 500 ohms \\
\hline Insulation resistance & $100 \mathrm{M}$ ohms \\
\hline Rebound time & $1 \mathrm{~ms}$ \\
\hline Key Operating Force & $150-200 \mathrm{~N}$ \\
\hline Life & 100 million (times) \\
\hline Operating Temperature & 60 degree C \\
\hline
\end{tabular}

Table 2: Specifications for mechanical properties

\begin{tabular}{|c|c|}
\hline Specification & Value \\
\hline Operating pressure & $170-397 \mathrm{~g}$ \\
Touch feeling & $(6-14 \mathrm{~Hz})$ \\
\hline Switch travel & $0.6-1.5 \mathrm{~mm}$ \\
touch-type & \\
\hline
\end{tabular}

Table 3: Specifications for environmental properties

\begin{tabular}{|c|c|}
\hline Specification & Value \\
\hline Operating temperature: & -40 to +80 \\
\hline Storage temperature: & 40 to +80 \\
\hline Temperature & $40 \mathrm{C}, 90 \%$ to $95 \mathrm{C}, 240 \%$ \\
hours.
\end{tabular}

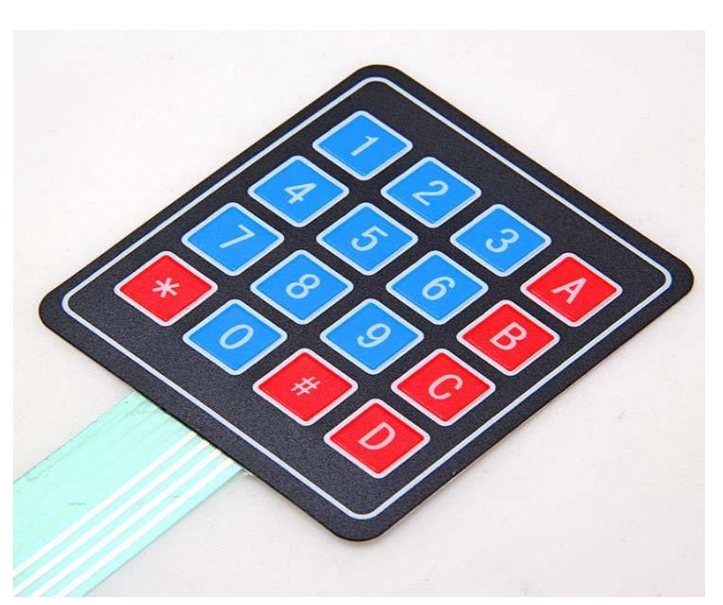

Fig 6: 4 x 4 Matrix Array

\subsection{LCD Display $20 \times 4$}

As shown in fig 7, the 0.96 inch LCD display is based on a popular SSD 1306 display controller [7]. It has a resolution of 128 x 64 pixels. Display controller libraries are available for Raspberry Pi, Arduino, AVR, PIC and ARM microcontrollers.

The specifications of LCD are given in the table 4 .
Table 4: Specifications of LCD display

\begin{tabular}{|c|c|}
\hline Specification & Value \\
\hline Active area: & $70.4 \times 20.8 \mathrm{~mm}$ \\
\hline Dot size: & $0.55 \times 0.55 \mathrm{~mm}$ Dot \\
\hline pitch: & $0.60 \times 0.60 \mathrm{~mm}$ \\
\hline Character size: & $2.96 \times 4.75 \mathrm{~mm}$ \\
\hline Character pitch: & $3.55 \times 5.35 \mathrm{~mm}$ \\
\hline LCD Type: & FSTN \\
View direction: & Wreen LCD \\
Backlight Type: & lead free \\
\hline RoHS Compliant: & -20 degree C to +70 degree C \\
\hline Operating Temperature: &
\end{tabular}

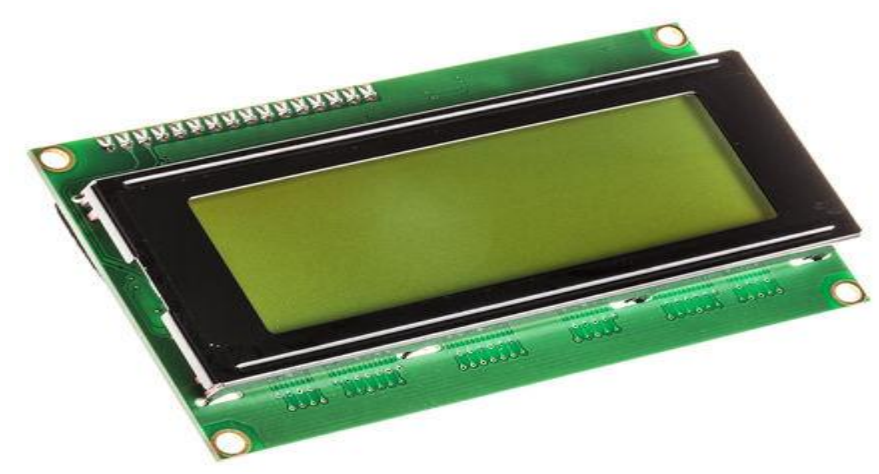

Fig 7: LCD Display

2.6 Servo Motor with door locking system The specifications [8] of the servo motor are given in table 5 .

Table 5: Specifications of Servo motor

\begin{tabular}{|c|c|}
\hline Specifications & Value \\
\hline Torque: & $1.8 \mathrm{~kg}-\mathrm{cm}(4.8 \mathrm{v})$ \\
\hline Speed: & $0.10 \mathrm{sec} / 60$ degree \\
\hline Weight: & $9 \mathrm{~g}$ \\
\hline Gear Type: & plastic \\
\hline Rotational Range: & 180 degree \\
\hline
\end{tabular}

The Motor will be connected to the motor driver circuit which will be connected to the Arduino board. The Arduino will give commands to the motor driver circuit whether to rotate the motor in anticlockwise or clockwise motion. This motion of the motor will lock the system slot or open the system slot. Based on the inputs given by the user the entire system will work accordingly. Door lock [1] is connected to the motor which will operate the locking system based on the commands given by the Arduino board. If the user enters the right password then the only the locking system will operate [9]. The servo motor is shown in fig 8. [9]. 


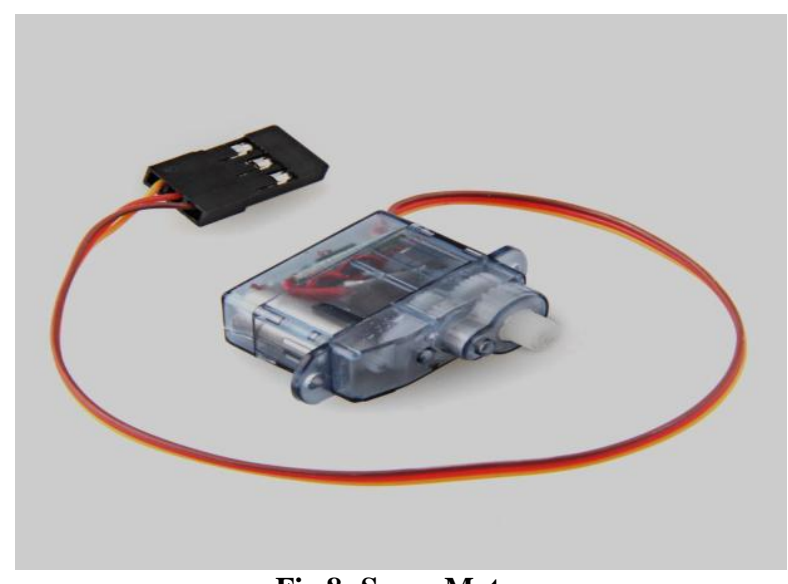

Fig 8: Servo Motor

\section{WORKING PRINCIPLE}

The coin insertion based mobile charging system has two important components which function as the heart and brain of the entire system. The Arduino UNO board is the brain of the system and is interfaced with all the other components and controls the entire system. The microcontroller is programmed in such a way that it takes the command from the coin insertion machine and accordingly it defines the time for which the phone will charge. The Arduino board is also interfaced with the keyboard and LCD where it takes the inputs from the keypad and displays instructions on the LCD display. The Arduino board also recognizes which slots are available and which slots are busy and will notify the user through displaying a notification. The Arduino board also provides the security to the slots which have a locking mechanism. It includes a metal lock which is driven by a motor and the motor is controlled by the motor driver circuit which is connected to the Arduino board. Depending upon the password entry the Arduino board creates password or verifies the password in order to open or close the slot with the help of motor driven metal lock provided to the slots. The coin insertion machine works on the principle of image processing. Once the user enters a specific coin for certain times then the various images are captured by the sensor present in the machine. These images are then processed and then identified by the value of the coin. Similarly the coin insertion machine can identify 4 such coins. Any other coin inserted into the coin insertion machine then will get rejected and will come out from the machine. Hence the entire system works efficiently with the help of all these principles and concepts. The designed system model and block diagram is as shown in fig 9 below [10],

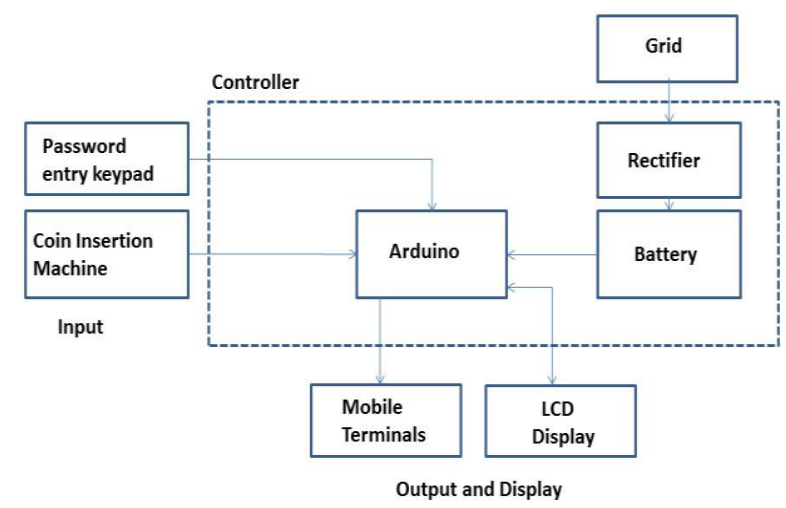

Fig 9: Block Diagram
The flowchart for the procedure user has to follow is given in fig 10 and 11 below:

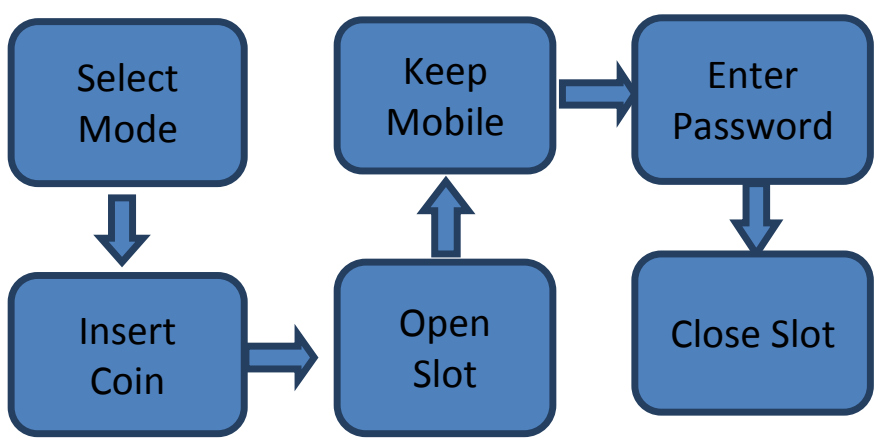

Fig 10: Flowchart (Part-1)

And after charging is completed,

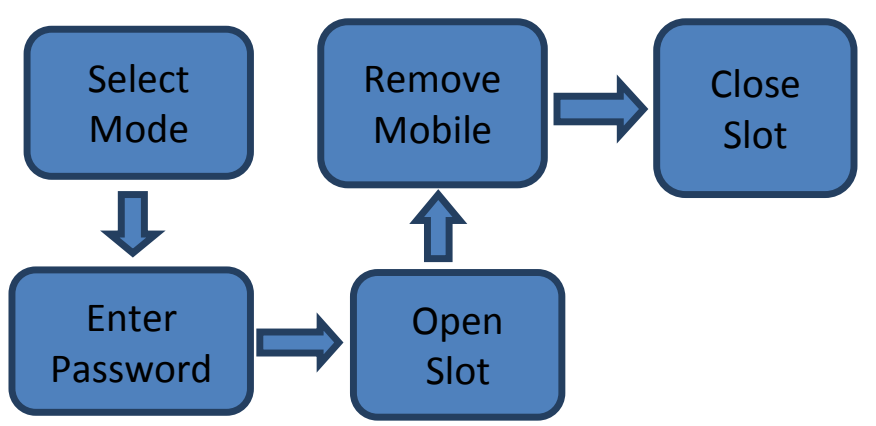

Fig 11: Flowchart (Part-2)

The main input is taken from $230 \mathrm{~V}$ AC mains power supply which then produces a $5 \mathrm{~V}$ DC output after being rectified by the $\mathrm{AC}$ to $\mathrm{DC}$ converter to charge each phone. The phones are charged using standard USB cables. The USB cables are connected to switches controlled by the Arduino which can turn them ON or OFF for particular amounts of time depending upon the money inserted by the user. This project being just a prototype, charging for only two phones was designed. However for large scale real life implementation, wherein much more number of phones and slots come into picture, power dissipation and high power and current needs to be taken into consideration. In such cases, use of heat sinks and high power components would become mandatory.

\section{CONCLUSION}

In this project, a coin insertion based mobile charging system is developed which can be installed at public places such as airports, railway stations, wherein users need to charge their phones as well as at places such as certain colleges and educational institutions wherein users are not allowed to take in their phones and can instead utilize that time for getting their devices charged. Interfacing of various components like the coin insertion machine, LCD, $4 * 4$ matrix keypad, servo motors with the Arduino microcontroller, and programming each of the components to function satisfactorily forms the heart of this project. This project can also be implemented at public places with an additional benefit of displaying advertisements in order to generate revenue.

\section{FUTURE SCOPE}

This project can be expanded in the future to include different charging mechanisms including the use of solar power[11] in 
case of a main line power failure, which can be extremely beneficial especially in rural areas where there are constant power cuts. Additionally, an OTP provided to the user on an alternate mobile number using GSM can also be provided for additional security. The entire system can also be connected online.

\section{REFERENCES}

[1] Yoshihiro Inomata, United States Patent Inomata US006999825B2, Filed: Dec. 21, 2001

[2] Chargetech Enterprises Pvt Ltd. www.chargetech.com

[3] Arduino UNO Board image, https://en.wikipedia.org/wiki/Arduino\#/media/File:Ardui no_Uno_-_R3.jpg

[4] Coin insertion machine image, http://www.openelectronics.org/buiding-an-arcade-coin-op-machine-torediscover-the-80-90s-with-retropie/

[5] AC to DC converter image, http://www.allaboutcircuits.com/technicalarticles/disasse mbl ng-a-rectifier/

[6] $4 * 4$ Matrix array keypad image, https://www.aliexpress.com/store/product/New-4-4-
Matrix-Array-Matrix-Keyboard-16-Key-Membrane-

Switch-Keypad-for-arduino-

3300/511826_1861994490.html

[7] LCD display image, http://uk.rs-online.com/web/p/lcdmonochrome-displays/7813052/

[8] Servo motor specifications, http://elementzonline.com/dc-motor-stepper-motordriver-board-with-1293d-ic- 84

[9] Servo motor image, http://circuitdigest.com/article/servomotor-basics

[10] M.S. Varadarajan, Coin Based Universal Mobile Charger, IOSR Journal of Engineering (IOSRJEN) ISSN:2250-3021 Volume 2, Issue-6, June 2012, PP 1433-1438v www.iosrjen.org

[11] Rohit Kamble, Sameer Yerolkar, Dinesh Shirsath, Bharat Kulkarni, Solar Mobile Charger, International Journal of Innovative Research in Computer Science and Technology(IJIRCST) ISSN:2347-5552, Volume-2, Issue-4, July- 2014. 